DIFFERENCE BETWEEN THE CONCEPTS OF A DISASTER INVESTIGATION ROBOT AND A DISASTER RESTRATION ROBOT

\author{
*Kenichi FUJINO $^{1}$, Keiji NAGATANI ${ }^{2}$, and Shinichi YUTA $^{3}$ \\ ${ }^{1}$ Incorporated Administrative Agency \\ Public Works Research Institution \\ 1-6, Minamihara, Tsukuba-city, \\ Ibaraki-Prefecture, Japan \\ (*Corresponding author: fujino@pwri.go.jp) \\ ${ }^{2}$ Tohoku University \\ 6-6-01, Aramaki-aoba, Aoba-ku, \\ Sendai, Miyagi, Japan \\ ${ }^{3}$ Shibaura Institute of Technology \\ 3-7-5, Toyosu, Koto-ku, \\ Tokyo, Japan
}




\title{
DIFFERENCE BETWEEN THE CONCEPTS OF A DISASTER INVESTIGATION ROBOT AND A DISASTER RESTRATION ROBOT
}

\begin{abstract}
Severe disasters have struck Japan in recent years. Following these disasters, construction robots have played important roles in investigation and restoration work in the disaster regions. To be applied in this way, construction robots require many functions according to the purpose of their use in each case. There are clear differences in the functions and usage conditions required by investigation robots and those required by execution robots. These differences will be important when designing and operating construction robots in the future. This report introduces a volcano exploration robot and unmanned execution system as examples of construction robots used for investigations and executions respectively. Based on this, the report organizes important characteristics of construction robots and explains differences in the concepts of disaster investigation robots and disaster restoration robots. Because they are used in harsh natural conditions and do not have any execution functions, efforts are made to clarify the fact that investigation robots have to overcome many problems such as mobility. When a construction robot is used, the scenario of the operation of the construction robot (execution plan) is extremely important, and in addition, it is necessary to clearly define the way it will be used according to the purpose of its use and specification conditions. In a plan for an unmanned execution system, it is possible to mitigate several strict prerequisite conditions by proposing a well-constructed execution plan. For example, the execution efficiency of an unmanned execution system can be improved by effectively using a temporary road.
\end{abstract}

\section{KEYWORDS}

Disaster countermeasure, exploration robot, unmanned execution system, field robotics

\section{INTRODUCTION}

Severe disasters have struck Japan in recent years. In particular, the Great East Japan Earthquake and accompanying tsunami inflicted severe damage in the Tohoku Region. This disaster also caused a serious radiation accident at the Fukushima Daiichi Nuclear Power Plant. In response to this earthquake, many volcanologists have predicted that a number of active volcanoes will erupt in the near future. So in Japan, we must establish monitoring systems to prepare for these types of disasters.

To carry out restoration after this disaster, construction robots were effectively used in dangerous zones and in contaminated districts. And these now bear important roles in Japan. For example, investigation robots are used to monitor the activity of volcanoes and execution robots are used to perform damage restoration work such as the execution of construction.

To use a construction robot, it must have many functions according to the purpose of its use. Recent use of these robots in Japan has revealed that there are many differences between the functions and usage conditions required to operate an investigation robot and an execution robot, and that users must design and operate robots very carefully.

\section{Purpose}

This report introduces volcano exploration robots and unmanned execution systems as examples of investigation robots and execution robots, in order to consider the effective design and use 
of construction of future robots. Based on this, the report considers the important characteristics of construction robots to explain differences in the functions required by a robot performing a disaster investigation and a robot executing disaster countermeasures.

\section{State of use of construction robots}

\section{Exploration robots}

To plan disaster restoration, it is extremely important to conduct an advance investigation. Therefore, in recent years, investigation robots have been used for advance investigations in dangerous places.

This report introduces a volcano exploration robot developed to perform exploration at Mt. Asama as an example. Mt. Asama is a famous volcano located in Japan.

\section{Purpose of Use}

Observe the state of volcanic activity on Mt. Asama

- Obtain images of the volcanic vent,

- Depth of volcanic ash at observation points, and

- Scale of volcanic products.

\section{Conditions}

- People are not permitted to approach the volcanic vent of Mt. Asama when it has erupted

- Robots are operated by radio from a safe place at least $4 \mathrm{~km}$ from the volcanic vent

- Data is measured at a fixed observation point and at several supplementary points as requested by the headquarters.

- The robot's functions can be selected according to required items, permitting costs to be reduced.

- The minimum required items are obtaining images of the volcanic vent and observation locations.

\section{$\underline{\text { Resolution Measures }}$}

When performing volcanic exploration, it is difficult to approach observation points. Figure 1 shows the normal state of a mountain trail. When a volcano has erupted, no one is permitted to enter a restricted area with a radius of $4 \mathrm{~km}$ from the volcanic vent. And there are probably many toppled trees in this area. And the robot must travel over volcanic ash to approach the volcanic vent. This means that it is important that the robot be mobile.

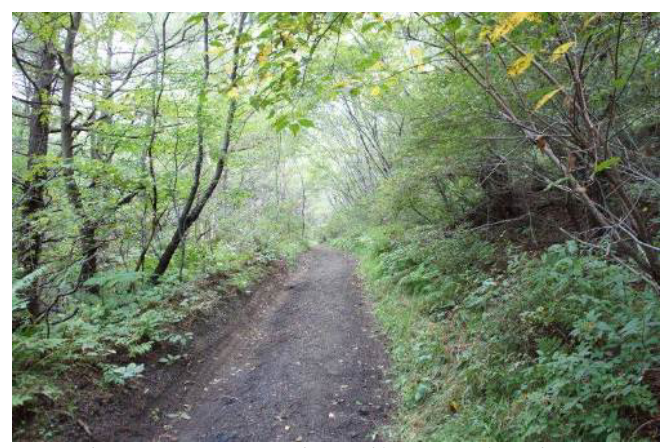

Figure 1- Mountain trail to a volcanic vent on Mt. Asama

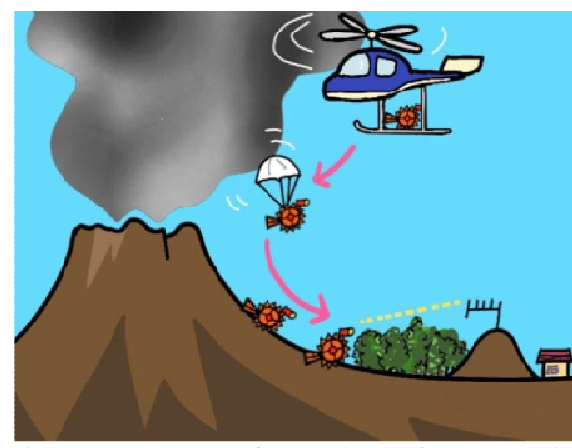

Figure 2 - Image of a method of approaching a volcanic vent 


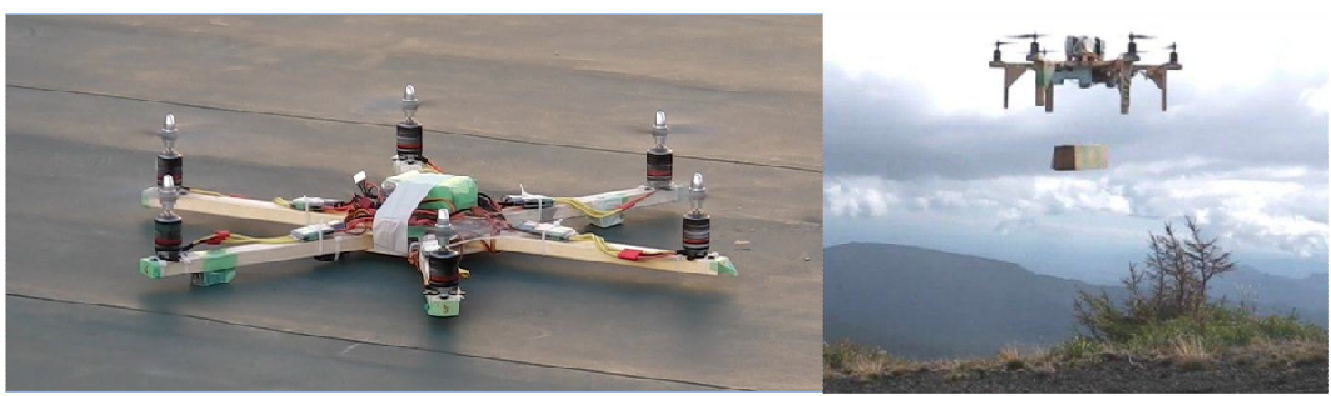

Figure 3 - Airborne robot Tobi, Tohoku University

We have proposed that volcano exploration robots be transported by air as a new approach method (Fig. 2).

This system consists of two robots. The flying robot TOBI, which is a kind of hex-rotor copter and the compact exploration robot, Geostar, which is transported to a place near a volcanic vent or to an observation point to collect a large quantity of information.

Geostar weighs $2.5 \mathrm{~kg}$. And its battery enables it to travel and make observations for two hours. We use the cell phone network, FOMA, to control Geostar. Because it is difficult to approach a volcanic vent, when it is used, Geostar is used and discarded as if it were on a one-way mission. Figure 3 shows the flying robot TOBI and Figure 4 shows the exploration robot, Geostar.
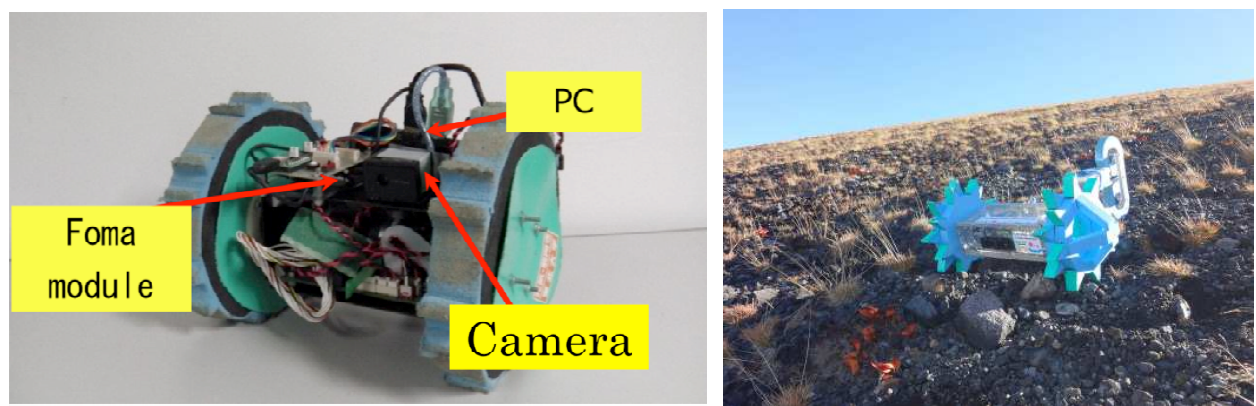

Figure 4 - Exploration Robot, Geostar, Tohoku University

Precautions

To prepare an effective disaster restoration plan, we must collect a large quantity of detailed site information in real time. But normally, the many important observation points required for the investigation are located in extremely dangerous areas. Therefore, "technology to approach the object of the investigation" provides a function that is generally extremely important for an observation robot.

\section{Execution Robot}

Execution is clearly the most important aspect of disaster restoration. In Japan, unmanned execution systems are used as disaster restoration work execution robots.

This report introduces, as an example, an unmanned execution system developed to be used for disaster restoration works at Mt. Unzan. Mt. Unzan, one of Japan's famous active volcanoes, erupted in 1990. After its eruption, an unmanned execution system was used for many of the disaster restoration works.

\section{$\underline{\text { Purpose of Use }}$}

We use execution robots to safely execute disaster restoration work in dangerous areas. 
(Volcanic eruptions, landslides, or earthquakes)

- Prevention of secondary disasters,

- Fast reconstruction, and

- Safety of the work

\section{$\underline{\text { Conditions }}$}

- Range of travel of robots is limited to the execution site.

- The minimum function required of an execution robot is that it be able to execute work to change the topography at the site.

- Because this type of work is earthwork, expensive robots made by modifying earthwork machines are necessary, making it difficult to keep the cost low.

solution

The principal part of disaster restoration work is earthwork. Figure 5 shows an unmanned execution system.

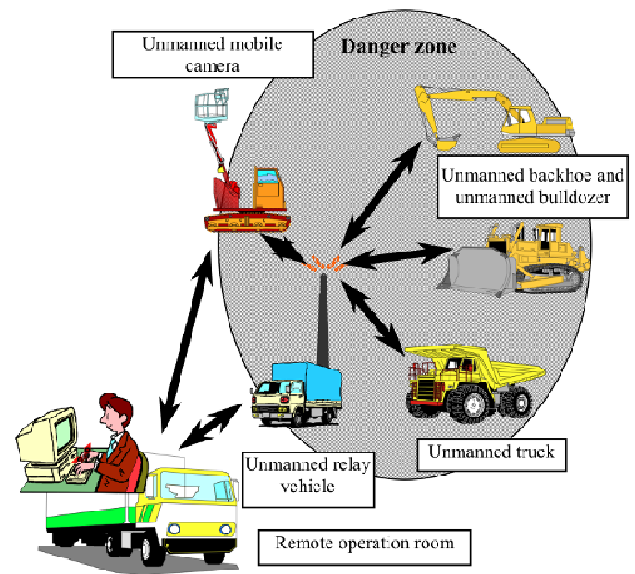

Figure 5 - Unmanned Execution System

Normally, an unmanned execution system consists of earthwork machines, such as a backhoe, bulldozer, and dump truck, which are operated from an operating room. If a wired system is used, there is a danger that the machines might cut the cables. So to operate many large construction machines and communicate with mobile cameras, a wireless communication system is used. And in many cases, fixed cameras connected with cables are used.

Figure 6 shows a disaster restoration work site. This is the typical state of a restoration work site. The many large rocks reduce trafficability. Therefore, it is extremely difficult to move the execution machines close to the objects of their work. But an unmanned execution system has a function which each machine uses to create a new road to approach its work. Therefore, the object approach function is not a very serious problem.

\section{$\underline{\text { Precautions }}$}

We have to use many large earthwork machines to perform effective executions. This is extremely expensive, and they require daily maintenance and refueling. This means that they have to be returned to their maintenance base from the execution site every day. And under normal circumstances, it is impossible for a robot and its operator to be very far apart. 


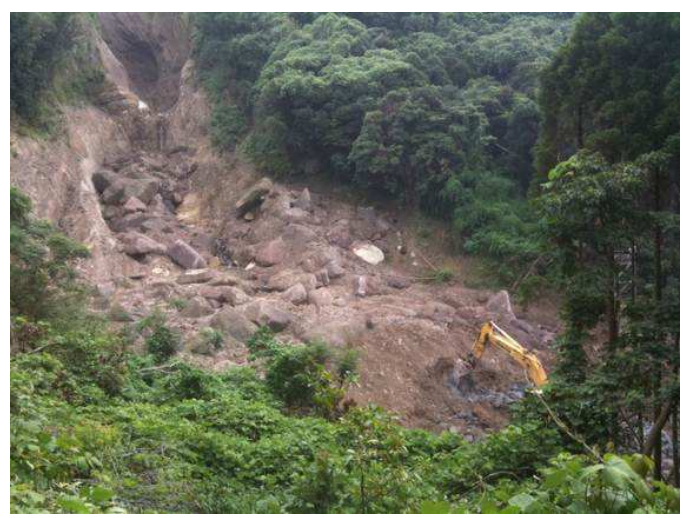

Figure 6 - Disaster Restoration Work Site (Landslide at Minamiosumi, JAPAN)

\section{Discussion}

We nave compared the functions of investigation robots and execution robots on Table 1.

\section{$\underline{\text { Work }}$}

Normally, an exploration robot is specialized for investigations and cannot perform executions on site. Therefore, an investigation robot cannot itself change the existing natural environment by executing work. And in order to start observations as quickly as possible, it must be moved rapidly to the investigation target. So mobility is an extremely important function.

An execution robot on the other hand, can build a road itself to approach the work site. And while it must execute its work rapidly, it does not have to approach the target quickly.

\section{$\underline{\text { Range of vision }}$}

Both types of robot must have a good range of vision in order to operate. But when an investigation robot is used, it is extremely difficult to arrange the fixed cameras at the measurement points in advance. Therefore, the camera on an investigation robot is generally used for two purposes. These are to operate the robot and observation.

When we use an unmanned execution system, we have to obtain a good range of work vision in order to work efficiently. At such times, we can use multiple fixed cameras at the execution site.

\section{Communications}

An investigation robot requires a radio coverage area far larger than an execution robot. So it is extremely effective to use a cell phone communications network. But there are cases where the disaster region is not covered by such a network. So before beginning an investigation, the range of use of the cell phone network must be confirmed.

When we use an execution robot, we must have a radio system to communicate continuously. And because on work sites, the range is limited, we can use a personal use radio network. In many such cases, it is possible to obtain an environment perfectly suitable for operation.

\section{$\underline{\text { Cost }}$}

Generally, investigation robots are equipped with a variety of observation use sensors. And execution robots are developed by modifying expense earthwork machines. Therefore, generally, execution robots are more expensive than investigation robots. Of course, we must reduce the cost of performing work, so we use execution robots over and over. If the tasks of investigation robots could be reduced, we could use disposable robots. 
Table 1 - Comparison of the Functions of Investigation Robots and Execution Robots

\begin{tabular}{|l|l|l|}
\hline \multicolumn{1}{|c|}{ Function } & \multicolumn{1}{|c|}{ Exploration Robot } & \multicolumn{1}{c|}{ Execution Robot } \\
\hline Work & $\begin{array}{l}\text { Investigation to predict and } \\
\text { evaluate the damage } \\
\text { Minimum work-Obtain images } \\
\text { of the state of the disaster } \\
\text { Important capability- Mobility }\end{array}$ & $\begin{array}{l}\text { Earthwork to restore the damage } \\
\text { Minimum work- execution } \\
\text { (earthwork) } \\
\text { Important capability - Mobility } \\
\text { Precaution-It is necessary to } \\
\text { perform daily maintenance and } \\
\text { refueling }\end{array}$ \\
\hline Range of vision & $\begin{array}{l}\text { Only a movable camera mounted } \\
\text { on a robot can be used. It is used } \\
\text { to operate the robot and to } \\
\text { observe the work. }\end{array}$ & $\begin{array}{l}\text { Because fixed cameras can be } \\
\text { installed at the execution site, } \\
\text { both they and movable cameras } \\
\text { can be used. And it is necessary to } \\
\text { obtain suitable real time images to } \\
\text { perform the execution. }\end{array}$ \\
\hline Communication & $\begin{array}{l}\text { The robot and operator are far } \\
\text { apart. And there are limits on the } \\
\text { robot's payload, so the radio } \\
\text { system tends to be weak. }\end{array}$ & $\begin{array}{l}\text { In many cases, the robot and } \\
\text { operator are relatively close } \\
\text { together. And it is possible to } \\
\text { prepare good radio equipment on } \\
\text { the execution site. }\end{array}$ \\
\hline Cost & $\begin{array}{l}\text { It is impossible to define costs } \\
\text { uniformly because the sensors } \\
\text { and function differ according to } \\
\text { environment. In some cases, it is } \\
\text { possible to use a disposable robot. }\end{array}$ & $\begin{array}{l}\text { The system and the equipment are } \\
\text { costly. So generally, robots are } \\
\text { used repeatedly. }\end{array}$ \\
\hline
\end{tabular}

\section{CONCLUSIONS}

This report briefly explains the differences between investigation robots and execution robots developed in recent years. It is intuitively easy to conclude that an investigation robot has fewer requirements than an execution robot, and that all it requires is a mechanical mechanism. But when we actually use investigation robots, we discover that while they can be used in harsh natural environments, they have no execution functions, so they cannot open their own roads, and require mobility and other functions that are difficult to provide.

And we must select tasks to perform using robots and robot functions in order to effectively design and actually operate robots according to the purpose and state of use. When starting a project to develop a construction robot, its purpose, usage conditions, and a scenario which defines its operation must be described. This is extremely important.

The most important key to applying construction robots is "planning".

\section{REFERENCES}

Keiji Nagatani (2013) Tele-operated observation for small-sized mobile robots in activated volcano areas. Journal of Erosion Control Engineering, submitting now.

Keiji Nagatani, Hiroaki Kinoshita, Kazuya Yoshida, Kenjiro Tadakuma, Eiji Koyanagi, (2011) Development of leg-track hybrid locomotion to traverse loose slopes and irregular terrain, Journal of Field Robotics, Volume 28, Issue 6, pp.950-960

Yoshio Ban (2002) Unmanned construction system: present status and challenges. 19th International Symposium on Automation and Robotics in Construction ISARC 2002 (pp 48-53) 